\title{
O Papel dos Ostensivos na Representação de Variáveis Estatísticas Qualitativas
}

\section{The Ostensive Role in the Representation of Qualitative Statistics Variables}

\author{
Irene Mauricio Cazorla* \\ ORCID iD 0000-0003-3028-5513 \\ Afonso Henriques $^{* *}$ \\ ORCID iD 0000-0002-8783-6008 \\ Cláudio Vitor Santana*** \\ ORCID iD 0000-0002-6830-871X
}

\begin{abstract}
Resumo
A essência da Estatística está na possibilidade de extração de informações relevantes a partir de dados coletados sobre aspectos da realidade. Para isso, os dados são transformados em tabelas, gráficos e medidas resumo. A compreensão dessas transformações pelo estudante é crucial para a aprendizagem. Neste artigo tecem-se reflexões teóricas sobre as ações de estudantes e o papel do material concreto manipulável como ostensivos na gestão e na representação de variáveis estatísticas qualitativas que sofrem transformações em diferentes registros semióticos. Para isso, utilizaram-se a Teoria dos Registros de Representação Semiótica e a Teoria Antropológica do Didático, essa última limitada à sua perspectiva de objetos ostensivos e não ostensivos. As reflexões indicam que a utilização dos ostensivos é motivadora no âmbito de ensino e aprendizagem. Assim, espera-se que as reflexões tecidas aqui contribuam para melhor compreensão e ensino de conceitos estatísticos, bem como para realização de novas pesquisas.
\end{abstract}

Palavras-chave: Variáveis Estatísticas. Dados Estatísticos. Ostensivos. Não-ostensivos. Registros de Representação.

\begin{abstract}
The essence of statistics is the possibility of extracting relevant information from data collected on aspects of reality. For this, the data are transformed into tables, graphs, and abstract measures. The student's understanding of these transformations is crucial for learning. In this article, we make theoretical reflections on the actions of students and the role of concrete material manipulated as ostensible in the management and display of qualitative statistics that undergo transformations in different semiotic records. For that, it uses the Theory of Semiotic Representation Records and the Anthropological Theory of Didactics, the latter limited to its perspective of

\footnotetext{
* Doutora em Educação pela Universidade Estadual de Campinas (Unicamp). Professora Plena da Universidade Estadual de Santa Cruz (UESC), Ilhéus, Bahia, Brasil. Endereço para correspondência: Rua Isolina Guimarães, 130, Apto. 102, Zildolândia, Itabuna, Bahia, Brasil, CEP: 45600-680. E-mail: icazorla@uol.com.br.

** Doutor em Matemática e Informática pela Universidade Joseph Fourier Grenoble, França. Professor Pleno na Universidade Estadual de Santa Cruz (UESC), Ilhéus, Bahia, Brasil. Endereço para correspondência: Rua Rosenaide Guimarães, 248, apto. 301, Zildolândia, Itabuna, Bahia, Brasil. CEP: 45600-702. E-mail: henry@uesc.br.

*** Mestre em Educação Matemática pela Universidade Estadual de Santa Cruz (UESC). Professor do Colégio Estadual de Educação Profissional em Biotecnologia e Saúde (CEEP), Itabuna, Bahia, Brasil. Endereço para correspondência: Rua Professora Juliana Larchet, 100, Conceição, Itabuna, Bahia, Brasil, CEP 45605-288. E-mail: clvitor@yahoo.com.br.
} 
ostensive and non-ostensive objects. The weightings indicate that the use of ostensive is motivating in the context of teaching and learning. Thus, it is expected that the reflections made here will contribute to a better understanding and teaching of statistical concepts, as well as to conducting new research.

Keywords: Statistical Variables. Statistical Data. Ostensive. Non-ostensive. Representation Records.

\section{Introdução}

Há mais de 20 anos os conteúdos de Estatística foram introduzidos oficialmente no currículo da Educação Básica no Brasil, com a publicação dos Parâmetros Curriculares Nacionais - PCN (BRASIL, 1997, 1998, 2006), e ratificados com a publicação da Base Nacional Comum Curricular - BNCC (BRASIL, 2018).

Nesse período, acompanhamos o desenvolvimento de uma comunidade de educadores estatísticos - tanto em nível nacional (CAZORLA; KATAOKA; SILVA, 2010; ESTEVAM; KALINKE, 2013; GUIMARÃES et al., 2009; WALICHINSKI; SANTOS JUNIOR; ISHIKAWA, 2014), quanto internacional (BATANERO, 2001; ZIEFFLER; GARFIELD; FRY, 2018) - que, preocupados com o ensino e a aprendizagem de conceitos estatísticos na Educação Básica, têm produzido artigos, dissertações, teses, livros e materiais didáticos de forma significativa.

Também presenciamos uma evolução sensível nos livros didáticos na apresentação desses conteúdos. Todavia, quando os analisamos, verificamos que a maioria ainda apresenta os conceitos a partir de situações dadas (BEZERRA; GUIMARÃES, 2017; DÍAZ-LEVICOY et al., 2016). Raramente, esses livros apresentam situações-problemas que envolvem a coleta de dados e o tratamento correspondente (SILVA, 2013).

Dessa forma, os estudantes aprendem a organizar os dados em tabelas, converter em gráficos, calcular as medidas resumos, mas não vivenciam a lógica da investigação estatística, não conseguem interpretar o significado das estatísticas produzidas e nem explicar por que uma estatística - no sentido de síntese dos dados, que podem ser gráficos, tabelas ou medidas resumo - é mais adequada do que outra, em diferentes contextos.

Nesse sentido, advogamos sobre a necessidade de os estudantes vivenciarem o significado real da Estatística, de modo a desenvolver o pensamento estatístico, que, segundo Wild e Pfannkuch (1999), pode ser entendido como as estratégias mentais associadas à tomada de decisão em todas as etapas do ciclo investigativo. Para isso, faz-se necessário pensar em situações-problemas que a Estatística possa ajudar a responder, no contexto escolar.

Com esse propósito, construímos várias sequências de ensino, para o contexto escolar, valorizando o papel ativo do estudante (CAZORLA; SANTANA, 2006; CAZORLA; 
SANTANA, 2010; CAZORLA et al., 2017) e utilizamos, na medida do possível, o apoio da ação do estudante e do material concreto manipulável, percorrendo as fases do ciclo investigativo (WILD; PFANNKUCH, 1999), com o objetivo de compreender o significado dos conceitos estatísticos em contexto, com vistas ao letramento estatístico, como postulado por Gal (2002).

Outros autores, como Arruda (2017), Buehring (2006), Souza (2007), Souza e Tinti (2013) também desenvolveram sequências de ensino utilizando materiais concretos manipuláveis.

Apesar de todo esse esforço, a nosso ver, ainda permanece um dos problemas do ensino de Estatística, que reside na dificuldade de os estudantes acompanharem as constantes transformações que os dados sofrem, nos diferentes registros. Isso devido ao fato de que os dados, numéricos ou categóricos, precisam ser registrados, organizados em listas, tabelas, rol ou banco de dados; tratados e analisados, o que implica na passagem do dado bruto para níveis cada vez mais complexos e sofisticados de abstração, próprios das representações estatísticas.

Dessa maneira, acreditamos que devemos dar mais atenção ao processo de transformar e representar os dados brutos de forma cada vez mais complexa e abstrata. Nesse contexto, no presente artigo objetivamos tecer reflexões sobre como um objeto ostensivo, a partir da mobilização dos objetos não ostensivos correspondentes, em diferentes registros semióticos, pode contribuir para a compreensão e a aprendizagem dos conceitos estatísticos que emergem das variáveis qualitativas.

Este artigo está organizado, além da introdução, em quatro seções. Na Seção 2, abordaremos a Estatística na Educação Básica, pontuaremos as orientações curriculares e delimitaremos os conceitos estatísticos subjacentes às variáveis qualitativas. $\mathrm{Na}$ Seção 3, apresentaremos o aporte teórico, considerando aspectos relevantes da Teoria dos Registros de Representação Semiótica (TRRS) para abordar os tratamentos e as conversões de dados qualitativos em diferentes registros e a Teoria Antropológica do Didático (TAD), restringindonos a sua perspectiva de objetos ostensivos e não ostensivos. Na Seção 4, exporemos o papel de alguns objetos ostensivos na transformação dos dados qualitativos em objetos estatísticos. Por fim, na Seção 5, teceremos considerações finais sobre as potencialidades e os limites da utilização de objetos ostensivos na apropriação dos conceitos estatísticos que emergem das variáveis qualitativas. 


\section{A Estatística na Educação Básica}

A introdução oficial dos conteúdos de Estatística no currículo da Educação Básica ocorreu no componente curricular de Matemática, no Ensino Fundamental, com a publicação dos Parâmetros Curriculares Nacionais - PCN (BRASIL, 1997, 1998), formando um dos quatro blocos definidos pelo documento, denominado "Tratamento da Informação"; e, no Ensino Médio, como um dos quatro eixos, denominado de Análise de Dados (BRASIL, 2006). Essa tendência foi ratificada na Base Nacional Comum Curricular - BNCC (BRASIL, 2018), que incluiu os conteúdos estatísticos em uma das cinco unidades temáticas, denominada "Probabilidade e Estatística".

Com base nesses documentos oficiais, sustentamos que os conceitos estatísticos que devem ser trabalhados na Educação Básica são:

- pesquisa amostral e censitária;

- leitura e construção de tabelas estatísticas simples e de dupla entrada, em especial a Tabela de Distribuição de Frequência (TDF);

- leitura e construção de gráficos: pictogramas, setores, barras/colunas, linhas, histograma, diagrama de ramo e folhas e diagrama da caixa (boxplot);

- medidas de tendência central (MTC): média, mediana e moda;

- medidas de dispersão (MD): amplitude, amplitude interquartílica, variância e desvio padrão;

- medidas de posição: primeiro e terceiro quartil para poder construir o boxplot.

A inserção do ensino de Estatística na Educação Básica, segundo Batanero (2001), desde os anos de 1970 se consolidou dentro de um movimento mundial devido à contribuição do pensamento estatístico e à necessidade de formar cidadãos capazes de ler o mundo, permeado de informações estatísticas.

Mas o que é Estatística? Definir Estatística é complexo, e não há unanimidade a esse respeito na comunidade científica. Todavia, todos concordam sobre a importância de seu ensino em todos os níveis educacionais. Para Wild, Utts e Horton (2018, p. 7), Estatística é uma metadisciplina que "transforma os dados em ideias do mundo real”. Já para Cobb e Moore (1997), a Estatística é uma disciplina metodológica que auxilia outros campos de conhecimento, fornecendo ferramentas para analisar dados.

Ainda, para Wild, Utts e Horton (2018), o rápido desenvolvimento da Estatística e das opções para o seu ensino desafia os educadores estatísticos a determinarem objetivos de 
aprendizagem e métodos instrucionais para alcançar melhor esses objetivos, campo que tem sido denominado de Educação Estatística. Para Zieffler, Garfield e Fry (2018), a Educação Estatística é um campo interdisciplinar focado no ensino e na aprendizagem de Estatística. Para Garfield e Ben-Zvi (2008), a Educação Estatística se ancora na Educação Matemática, que fornece arcabouços teóricos metodológicos da pesquisa relativa à aprendizagem e ao desenvolvimento da cognição, mas que evoluiu como um campo independente de investigação.

Neste trabalho, assumimos Estatística como um campo de conhecimento que tem como fim desenvolver ferramentas para transformar em tabelas, gráficos e medidas resumo os dados brutos, obtidos de uma situação ou de um fenômeno em estudo, para extrair informações relevantes, padrões, regularidades e relações entre as variáveis, visando sua descrição e compreensão, conforme Figura 1.

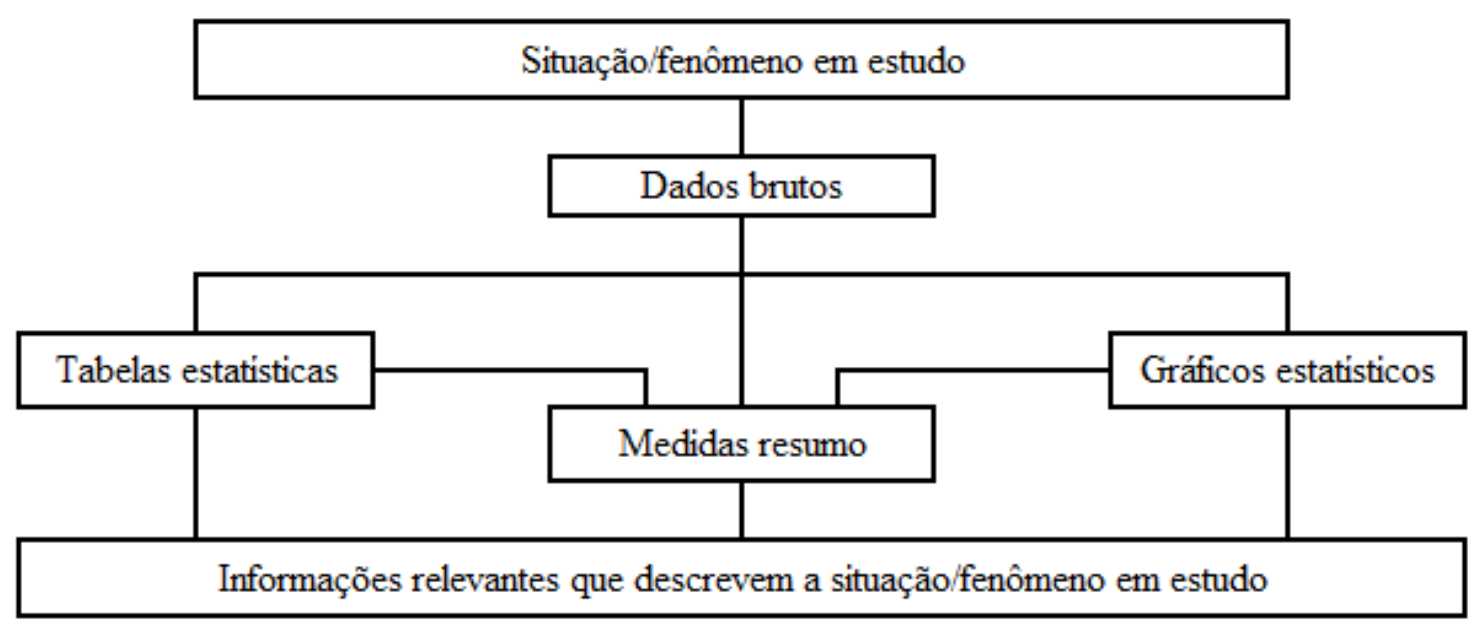

Figura 1 - Percurso da Estatística na transformação dos dados em representações estatísticas Fonte: Elaborada pelos autores (2020).

Isso posto, no tocante à aprendizagem dos conceitos estatísticos, um dos problemas enfrentados pelos estudantes reside, justamente, na compreensão das transformações que os dados sofrem durante a sua análise, pois eles são tratados, resumidos e convertidos em diferentes registros.

Desse modo, a seguir, delimitamos os conceitos estatísticos de base, subjacentes às variáveis estatísticas qualitativas, que abordamos neste artigo, tais como: variável, dados, tabelas, gráficos e medidas resumo, em conformidade com a Figura 2.

Segundo Cazorla, Santana e Utsumi (2019, p. 10), os conceitos de variável e de dados são chaves para a Estatística, pois se constituem em sua matéria-prima:

As variáveis medem ou descrevem as características da população em estudo, e podem ser qualitativas (geram categorias), como, por exemplo, sexo, raça, região, ou quantitativas (geram números) e, dentre estes, as discretas (resultado de contagem), como, por exemplo, número de filhos por mulher, número de pessoas de um país, ou as contínuas (resultado de mensuração), como, por exemplo, altura e peso (massa corpórea) de uma pessoa, renda familiar etc. 
Neste artigo focamos as transformações quando analisamos uma variável qualitativa, denominada "análise univariada", como sistematizamos na Figura 2, que passaremos a analisar.

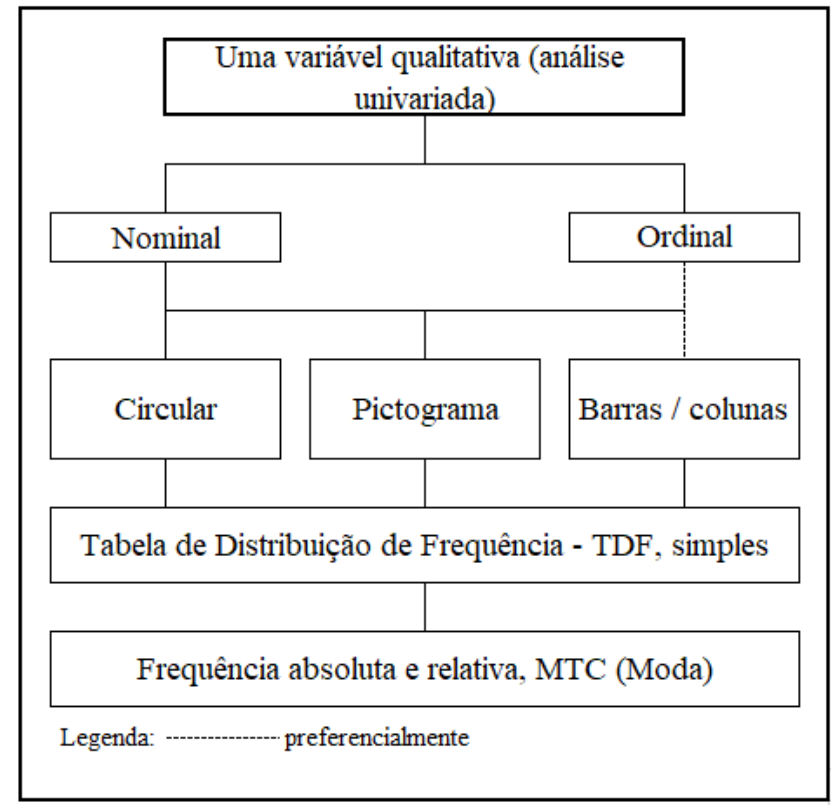

Figura 2 - Possíveis transformações dos dados brutos de uma variável qualitativa Fonte: Elaborada pelos autores (2020).

Uma tabela é uma organização matricial que contém dados. Se esses dados já tiverem sido tratados estatisticamente, então será uma tabela estatística. Um caso particular é a Tabela de Distribuição de Frequência (TDF), que, neste caso, será categórica (variáveis qualitativas). Se estamos analisando uma única variável, a tabela é denominada de "simples" e é formada pelas categorias da variável em estudo e a frequência absoluta com que ocorre cada uma delas e, também, pode ser acompanhada da frequência relativa.

Um gráfico estatístico, segundo Cazorla (2002), é uma representação simbólica de dados, geralmente relacionando duas ou mais variáveis estatísticas. No caso de uma variável qualitativa, o gráfico associará as categorias da variável à frequência com que ocorre cada uma delas.

Quanto às medidas resumo para as variáveis qualitativas, temos as frequências absolutas e relativas, e a única medida de tendência central que podemos encontrar é a Moda, que é a categoria que ocorre com maior frequência.

Isso posto, apresentamos o quadro teórico em que nós apoiamos para analisar a contribuição da ação dos sujeitos e dos materiais concretos manipuláveis como objetos ostensivos na representação de variáveis estatísticas qualitativas.

Enfatizamos que o escopo deste trabalho está restrito ao contexto da Educação Básica, à análise univariada e ao ambiente papel-lápis, sem explorar os ambientes computacionais. 


\title{
3 Quadro teórico
}

Segundo Henriques (2019, p. 37), na literatura existem muitos referenciais teóricos, e o pesquisador escolhe dessa gama um Quadro Teórico de base, definido como "o referencial teórico de base de uma pesquisa, escolhido pelo pesquisador em função da sua problemática, constituído, pelo menos, por uma teoria capaz de fornecer ferramentas de análise aos estudos que se pretende desenvolver".

Assim, buscando elementos teóricos capazes de fundamentar a nossa pesquisa em função da nossa problemática, escolhemos o quadro teórico constituído pela Teoria dos Registros de Representação Semiótica (TRRS), desenvolvida por Duval (1993, 1995), e a Teoria Antropológica do Didático (TAD), proposta por Chevallard (1992).

Mais especificamente na $\mathrm{TAD}$, restringimos as nossas análises à perspectiva de objetos ostensivos e não ostensivos, pois, a nosso ver, esses objetos permitem explicar o potencial dos materiais concretos manipuláveis como ostensivos apropriados à representação de dados estatísticos a partir da mobilização mental dos objetos não ostensivos inerentes, bem como a observação e análise das ações dos estudantes.

\begin{abstract}
Os ostensivos são todos os objetos que têm uma natureza sensível, certa materialidade que, com efeito, adquirem para o sujeito humano uma realidade perceptível. Os objetos não-ostensivos são objetos que, como as ideias, as intenções ou os conceitos, existem institucionalmente sem, no entanto, poderem ser vistos, ditos, entendidos, percebidos ou mostrados por si: eles só podem ser evocados ou invocados a partir da manipulação adequada de objetos ostensivos associados (HENRIQUES, 2019, p. 65).
\end{abstract}

Com este referencial teórico analisamos o papel do material concreto manipulável e a ação do estudante na transformação dos dados estatísticos, uma vez que esse processo perpassa pela mobilização de objetos ostensivos e não ostensivos em cada registro de representação considerado.

Para definir material concreto manipulável ou recursos didáticos manipuláveis, ancoramo-nos em Henriques (2019, p. 33), que os define como "todo instrumento ergonômico e cognitivo, tangível a mão livre, capaz de permitir a gestão de conhecimentos, sendo, portanto, útil no processo ensino-aprendizagem de objetos de saberes institucionais".

Também recorremos à TRRS, uma vez que os dados brutos são tratados e convertidos em diferentes registros de representação semiótica.

Segundo Duval (1993), um registro de representação é um sistema semiótico dotado de signos que permitem identificar uma representação de um objeto de saber. $\mathrm{O}$ autor distingue três atividades cognitivas relacionadas ao sistema semiótico:

Primeiramente, constituir um traço ou um conjunto de traços perceptíveis que sejam 
identificáveis como uma representação de alguma coisa em um determinado sistema. Em seguida, tratar as representações apenas pelas regras próprias do sistema, de modo a obter outras representações que possam constituir uma relação de conhecimento em comparação às representações iniciais. Enfim, converter as representações produzidas em um sistema para representações correspondentes em outro sistema, de tal maneira que estas últimas permitam explicar outras significações relativas ao que é representado (DUVAL, 2009, p. 36-37).

As referidas regras, próprias do sistema, também designadas regras de conformidade, devem ser respeitadas na formação de uma representação semiótica, tais como regras gramaticais, quando se trata da descrição do conceito na língua materna, como regras de representação gráfica ou traços de desenhos geométricos no plano ou no espaço. Essas atividades encontram um espaço significativo no ensino e na aprendizagem de Estatística.

A título de ilustração, podemos ver, na Figura 3, as diversas representações dos dados da variável "cor favorita da turma". A primeira representação, que denominamos "real", ocorre quando uma criança veste uma camisa de sua cor favorita. A segunda, designada "icônica" ou "pictórica", revela-se quando utilizamos figuras ou ostensivos que representem a cor - neste caso, figura de camisa colorida. Podemos também representar verbalmente, escrevendo o nome da cor da camisa, neste caso "vermelha", e gráfica, quando consideramos um quadradinho que compõe o gráfico de barras em uma malha quadriculada.

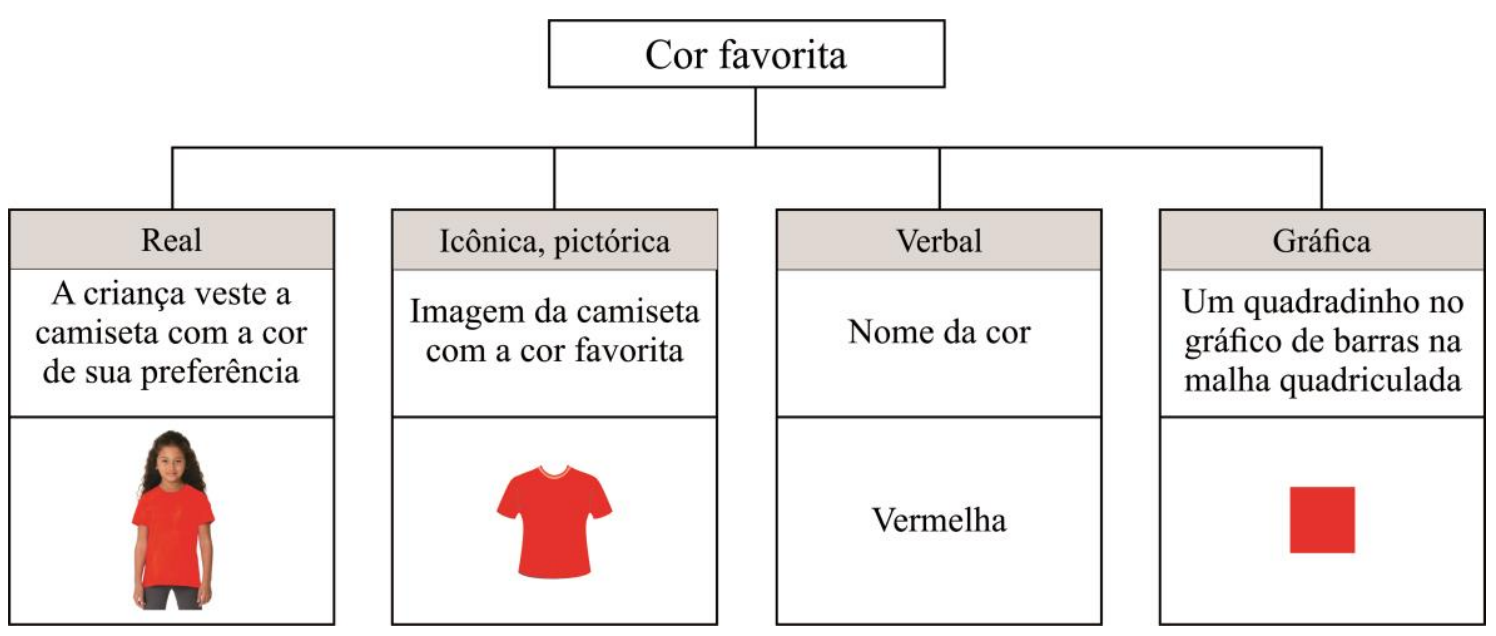

Figura 3 - Diversos tipos de representação da variável "cor favorita" Fonte: Elaborada pelos autores (2020).

Além da representação inicial, os dados devem ser organizados e tratados, sofrendo assim uma série de transformações. Contudo, nos questionamos: como podemos ensinar Estatística explicitando os diversos tratamentos e conversões de representações semióticas, a fim de evidenciar a essência dos dados?

Retomando as três atividades cognitivas relacionadas ao sistema semiótico, encontramos na TRRS quatro princípios ou elementos teóricos que julgamos essenciais nas referidas transformações e, consequentemente, no ensino, que são: representação ou formação, 
tratamento, conversão e coordenação.

- A representação ou formação é a construção da ideia em um registro, mobilizando alguns signos e regras de conformidade. No caso das variáveis qualitativas que geram categorias, como vimos na Figura 3, podemos utilizar uma representação real, icônica, verbal ou gráfica.

- O tratamento se processa quando as transformações de uma representação semiótica são realizadas no mesmo registro no qual o objeto foi representado, mobilizando os signos e as regras de conformidade no interior desse registro ou sistema. Por exemplo, transformar a frequência absoluta em relativa, conservando o registro numérico.

- A conversão ocorre quando há transformação da representação de um objeto a partir do registro no qual foi construído para outro, ou seja, na transformação, o que muda é a representação do objeto do registro de origem para outro, de forma a conservar o mesmo objeto. Por exemplo, a transformação dos dados de uma TDF para um gráfico de barras. Nesse tipo de transformação, destacamos dois aspectos: a manutenção do mesmo objeto e a conversão. No primeiro, a representação não pode ser confundida com o objeto, e muito menos com o registro utilizado. No segundo, a conversão pode evidenciar características ou informações distintas do mesmo objeto nos diferentes registros.

- A coordenação caracteriza-se pela assimilação conceitual do objeto, isto é, a capacidade do sujeito de identificar o mesmo objeto nas mais variadas representações nos diferentes registros, sem confundir o objeto com os respectivos registros. Por exemplo, a capacidade de reconhecer a representação dos dados estatísticos de um mesmo objeto representado em uma TDF ou em gráfico de barras (registro numérico ou gráfico). A manipulação de representações nos diferentes registros caracteriza-se, também, pela manipulação de diversos conceitos estatísticos.

A Estatística disponibiliza ferramentas que transformam os dados brutos, organizandoos em listas, banco de dados, planilhas (representação e formação) e, a partir dessa transformação, podemos agrupar dados em tabelas, converter em gráficos e calcular medidas resumo que denominamos "transformações primárias". Também podemos transformar dados representados em tabelas para gráficos e vice-versa; podemos partir de um gráfico de setores para um gráfico de barras ou pictograma, por exemplo, que denominamos de "transformações secundárias". A TRRS, assim como as noções de objetos ostensivos e não ostensivos, encontra um espaço significativo em Estatística, favorecendo a tomada de decisões.

De fato, em alguns casos, no tratamento de objetos estatísticos, podemos realizar um 
movimento reverso, como, por exemplo, reconstituir os dados de uma tabela a partir de um gráfico. Isso nem sempre é possível, pois, no processo de resumir os dados em categorias ou intervalos, podemos perder os dados originais, conforme Figura 4.

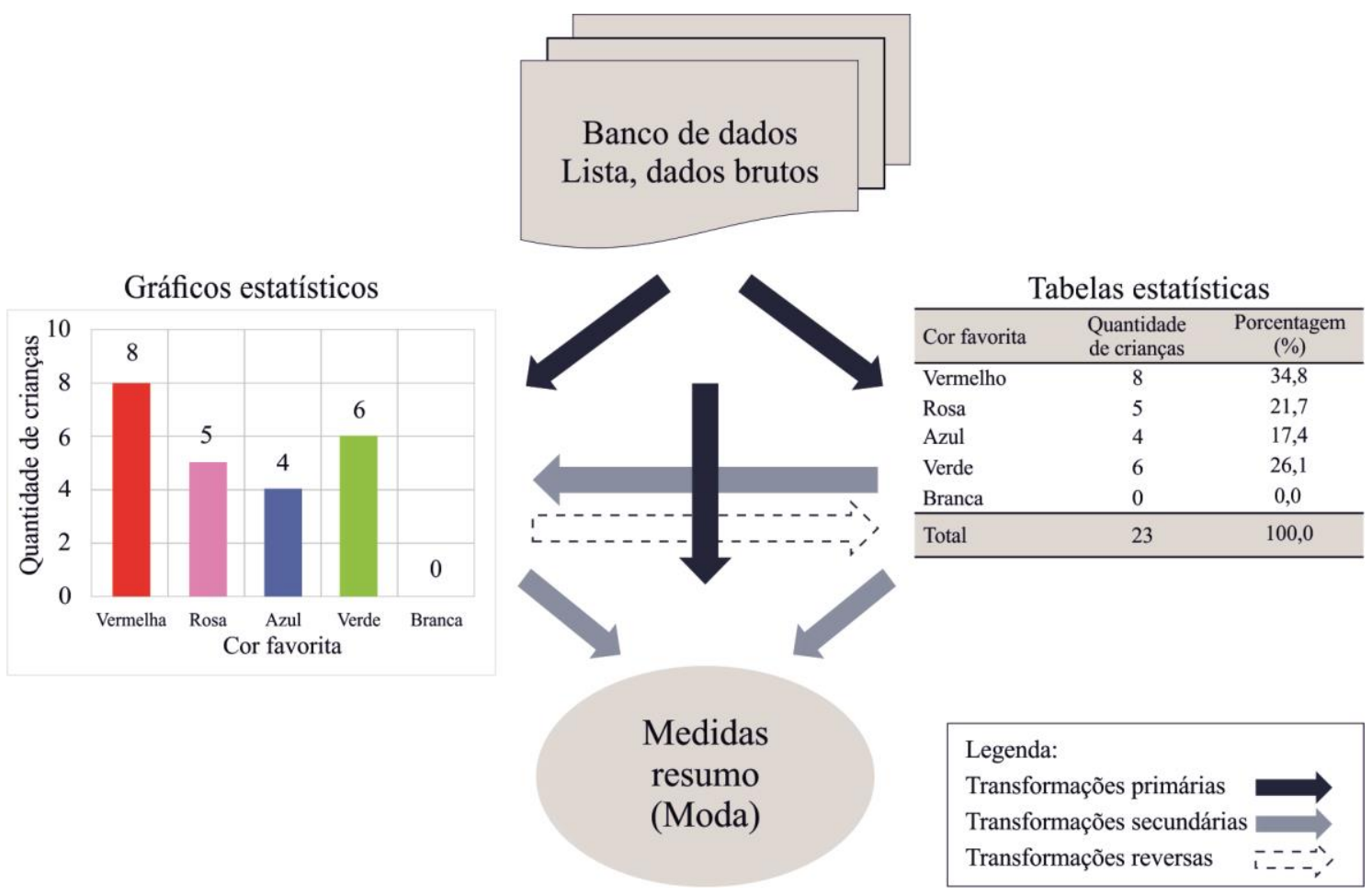

Figura 4 - Transformações de representação de dados estatísticos entre registros Fonte: Adaptada da Figura 3, de Silva Júnior (2018, p. 27).

Com esses antecedentes teóricos, estamos prontos para a análise e a gestão dos dados estatísticos de variáveis qualitativas em suas diversas representações.

\section{Os ostensivos na representação de variáveis estatísticas qualitativas}

Como já mencionado, nos deteremos à análise univariada de variáveis qualitativas, apropriada para os anos iniciais do Ensino Fundamental.

A Estatística, por essência, analisa grande volume de dados, mas em situações de ensino devemos trabalhar com uma quantidade razoável, que possa ser tratada em sala de aula. Embora não concordemos com a utilização de poucos dados para apresentar as ideias iniciais, temos consciência de que, às vezes, esta estratégia é a única saída, especialmente, quando trabalhamos com crianças pequenas.

Isso posto, a seguir, analisamos a utilização dos ostensivos na representação das variáveis qualitativas.

Suponhamos que desejemos conhecer a "Cor favorita da turma", em uma situação de 
ensino com crianças nos Anos Iniciais do Ensino Fundamental ou da Educação Infantil. A variável "Cor favorita" é qualitativa nominal, cujo tratamento estatístico pode passar pela mobilização de objetos ostensivos, uma vez que as crianças podem vivenciar a transformação dos dados, como, por exemplo, vestindo uma camiseta da cor favorita (Figura 3a).

Isso pode ser realizado com outras variáveis, como a "fruta favorita", escolhendo uma fruta de um cesto de frutas; ou a brincadeira favorita, com objetos que representem essas brincadeiras etc. Certamente, nem toda variável qualitativa poderá possibilitar o grau de ostensividade capaz de mobilizar a ação do próprio estudante, mas isso não impede de utilizar outros ostensivos, como veremos mais adiante.

Uma variável qualitativa nominal, tal como a cor favorita, é um adjetivo ou conhecimento controlado pelo sujeito ou por um instrumento mediante a manipulação de objetos ostensivos. À medida que essa variável assume diferentes categorias (isto é, a cor preferida), modifica-se o padrão do objeto ostensivo. De fato, suponhamos que tenhamos um cesto cheio de camisetas de cinco (número arbitrário) cores (vermelha, verde, rosa, azul e branca), todas serão padronizadas.

Nesta situação, as perguntas que emergem são as seguintes: “quais são as possíveis representações dos dados?”, “como acontecem as transformações, tratamentos e conversões destes dados entre diferentes registros de representação possíveis em Estatística, até obter-se uma descrição do comportamento padrão dessa variável?".

No caso da cor favorita (Figura 3), temos a representação real, a icônica, a verbal (porque estamos diante de uma variável qualitativa que gera categorias) e a gráfica.

Uma vez os dados levantados, o passo seguinte é organizá-los e resumi-los, a fim de descrever de forma sucinta a variável "Cor favorita da turma". Para isso, a Estatística disponibiliza tabelas, gráficos e medidas resumo. Mas antes podemos utilizar os ostensivos, para que a criança possa acompanhar as transformações dos dados nas "estatísticas", a partir da manipulação direta, à mão livre.

Se as crianças estão vestindo as camisas coloridas, podemos solicitar a elas que se alinhem segundo a cor, como mostramos na Figura 5a. Podemos dar às crianças camisetas de cartolina colorida e solicitar que elas as colem no quadro (Figura 5b); ou ainda podemos dar o cubo estatístico (SOUZA; TINTI, 2013; CAZORLA; SANTANA, 2020) para que pintem uma face com a cor favorita e depois empilhem os cubos, como mostramos na Figura 5c.

Nestes três casos, as crianças têm uma relação direta (de forma ostensiva) com as categorias da variável "cor favorita”, movimentando-se na sala de aula. 


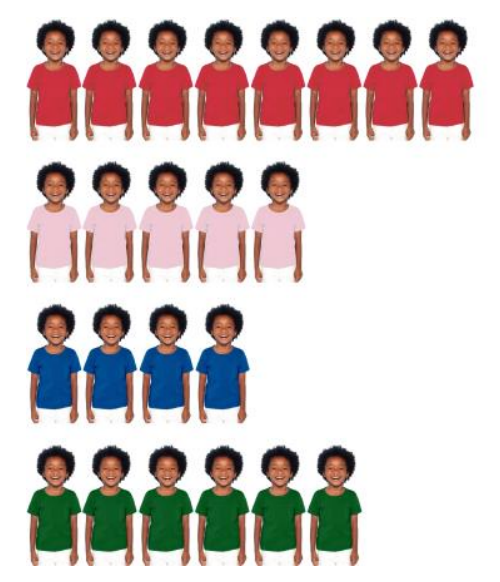

(a) vestindo camisetas coloridas

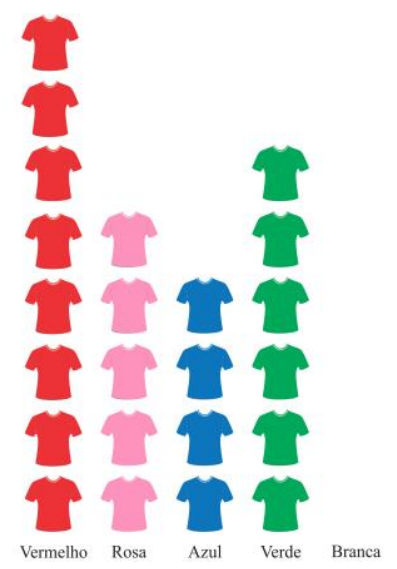

(b) utilizando camisetas de cartolina

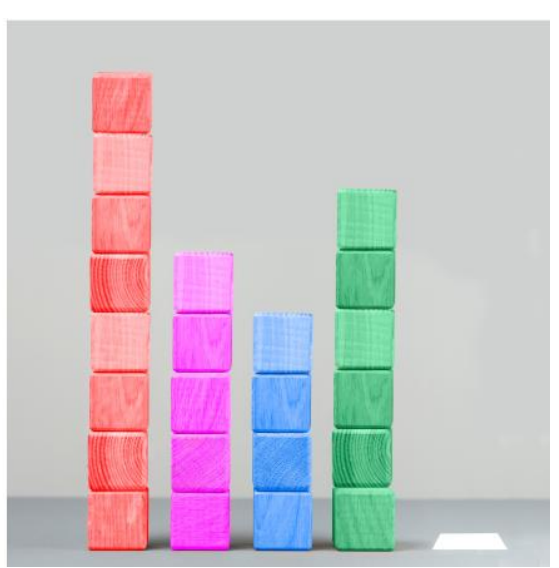

(c) utilizando o cubo estatístico

Figura 5 - Organização e representação da variável "cor favorita da turma" utilizando ostensivos Fonte: Elaborada pelos autores (2020).

A seguir podemos representar esses dados em gráfico de barras, pintando quadradinhos com a cor favorita, na malha quadriculada (Figura 6a), e depois pintando as barras contínuas, com a altura igual à quantidade de crianças que escolheram cada cor (Figura 6b). Neste caso particular, a cor das barras ainda é elemento ostensivo, mas os outros elementos são não ostensivos.

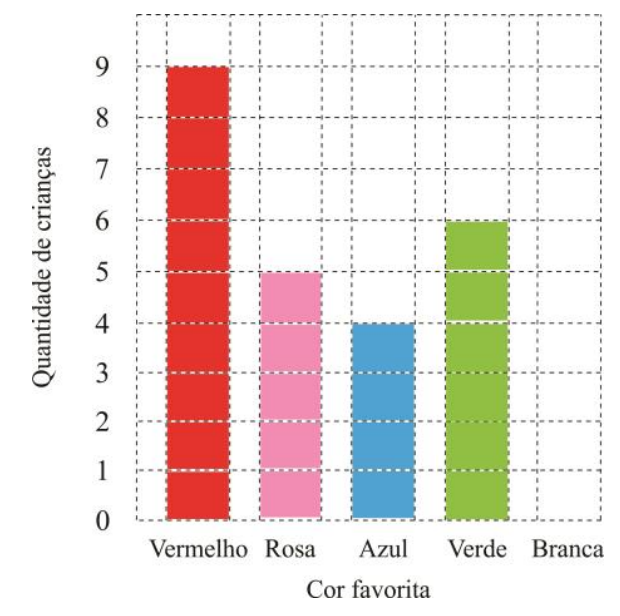

(a) Gráfica - com malha quadriculada

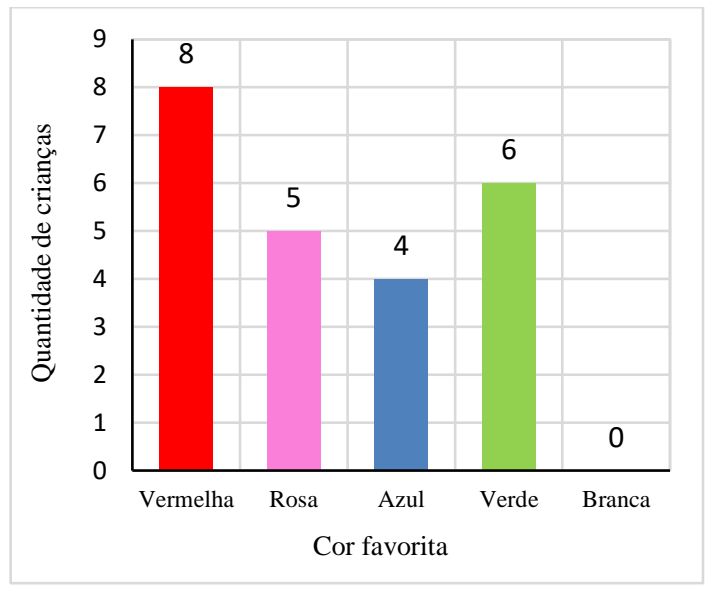

(b) Gráfica - com barras contínuas

Figura 6 - Organização e representação da variável "cor favorita da turma" utilizando ostensivos e não ostensivos

Fonte: Elaborada pelos autores (2020).

Também podemos utilizar os rótulos para sinalizar a altura das barras. Isto é importante, principalmente, quando uma categoria não recebeu indicações, pois o zero também é um dado, especialmente quando se trabalha com crianças pequenas, que acreditam que o zero não é dado, como mostram os resultados de Strauss e Bichler (1988).

Esse trabalho pode ser feito no quadro ou na cartolina e, se solicitarmos que cada criança pinte um quadradinho na malha quadriculada, ela ainda pode fazer uma correspondência entre 
o seu dado e o quadradinho que ela pintou na malha. Já no gráfico com a barra contínua não existe mais a correspondência biunívoca entre o dado da criança e a representação; isto é, esse tipo de gráfico requer que a criança saiba que o seu dado está contido na barra, o que exige um nível de abstração maior.

Ainda, na utilização de ostensivos podemos solicitar às crianças que formem um círculo, de acordo com a cor das camisas, e dar, a cada uma delas, fitas coloridas correspondentes, para fazer a ligação entre elas e o(a) Professor(a) que está no centro do círculo (Figura 7a) e, posteriormente, construirmos o gráfico de setores, mobilizando os objetos ostensivos como círculo decomposto em setores; as diferentes cores notáveis sobre os setores e os objetos não ostensivos associados, tais como a noção entre parte e todo, a porcentagem, a noção de setores (ângulo) de um círculo e a noção de gráfico circular (Figura 7b).

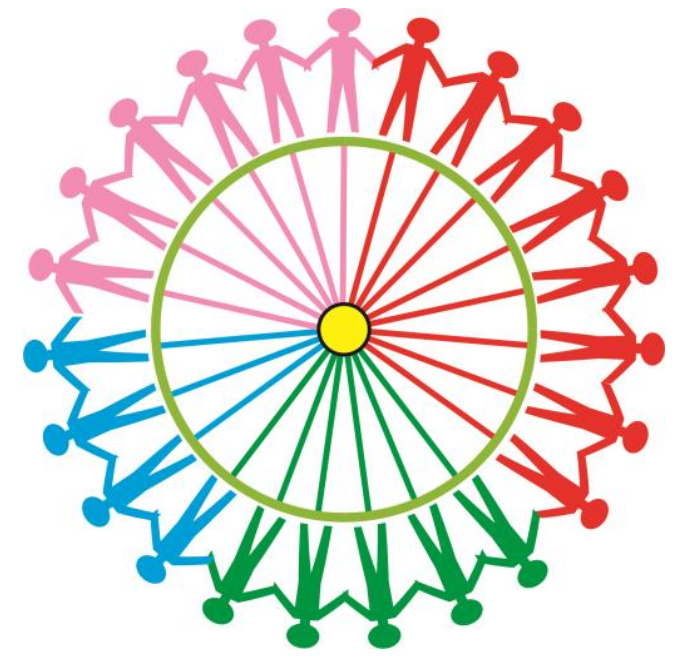

(a) Representação ostensiva do gráfico circular

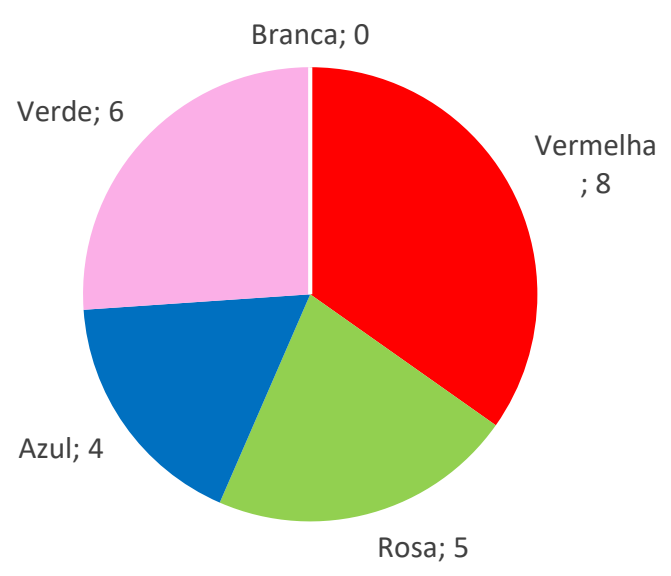

(b) Representação ostensiva e não ostensiva do gráfico circular

Figura 7 - Organização e representação da variável "cor favorita da turma", utilizando ostensivos e não ostensivos com o gráfico circular

Fonte: Construção dos autores (2020).

Observamos a importância dos rótulos que nomeiam as categorias e, neste caso, nós os acompanhamos com a frequência absoluta. Poderíamos ter utilizado a legenda, que é um componente do gráfico; contudo, por estarmos trabalhando com uma única variável, os rótulos escritos ao lado dos setores são mais eficientes na extração da informação. Colocar o nome e a quantidade pode parecer redundante; contudo, parece ser uma boa estratégia quando se trabalha com crianças na fase da alfabetização.

Por fim, passamos para a representação numérica. Para isso construímos uma TDF, que é uma tabela composta pelas categorias da variável, neste caso, "cor favorita" que tem cinco categorias: Vermelho, Rosa, Azul, Verde e Branca, acompanhadas da contagem e da representação numérica da quantidade de crianças que escolheram cada cor, isto é, a "frequência 
absoluta", conforme Figura 8a.

Em geral, na versão final das tabelas que vão ser utilizadas na comunicação dos resultados (Figura 8b) não se utiliza a palavra técnica "Frequência" nem o termo "Quantidade" - via de regra, utiliza-se "Número de ...". Esse é o jargão estatístico utilizado.

\begin{tabular}{|c|c|c|}
\hline Cor favorita & Contagem & $\begin{array}{l}\text { Quantidade } \\
\text { de crianças }\end{array}$ \\
\hline Vermelho & 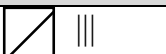 & 8 \\
\hline Rosa & 1 & 5 \\
\hline Azul & & 4 \\
\hline Verde & 1 & 6 \\
\hline Branca & & 0 \\
\hline Total & & 23 \\
\hline
\end{tabular}

(a) Construção da TDF

\begin{tabular}{ccc}
\hline Cor favorita & $\begin{array}{c}\text { N. }^{\circ} \text { de } \\
\text { crianças }\end{array}$ & $\begin{array}{c}\text { Porcentagem } \\
(\%)\end{array}$ \\
\hline Vermelho & 8 & 34,8 \\
Rosa & 5 & 21,7 \\
Azul & 4 & 17,4 \\
Verde & 6 & 26,1 \\
Preto & 0 & 0,0 \\
\hline Total & 23 & 100,0 \\
\hline
\end{tabular}

(b) Formato final da TDF

Figura 8 - Representação numérica da "cor favorita da turma” em formato tabular, utilizando não ostensivos Fonte: Construção dos autores (2020).

$\mathrm{Na}$ Tabela 1 aproveitamos para expor os diversos tratamentos que a frequência absoluta sofre para ser expressa em números relativos (parte/todo), que podem ser apresentados utilizando frações, números decimais (probabilidade) e porcentagem.

Tabela 1 - Distribuição de frequência da "cor favorita da turma"

\begin{tabular}{ccccc}
\hline \multirow{2}{*}{ Cor favorita } & $\begin{array}{c}\text { Frequência } \\
\text { absoluta }\end{array}$ & Fração & Probabilidade & Porcentagem (\%) \\
\cline { 3 - 5 } Vermelha & 8 & $\frac{8}{23}$ & 0,35 & 34,8 \\
Rosa & 5 & $\frac{5}{23}$ & 0,22 & 21,7 \\
Azul & 4 & $\frac{4}{23}$ & 0,17 & 17,4 \\
Verde & 6 & $\frac{6}{23}$ & 0,26 & 26,1 \\
Preto & 0 & 0 & 0,00 & 0,0 \\
\hline Total & 23 & 1 & 1,00 & 100,0 \\
\hline
\end{tabular}

Em geral, a TDF é acompanhada da frequência relativa em porcentagem. Nesse sentido, devemos checar a adequação de trabalharmos esse conceito, examinando o ano escolar em que estamos desenvolvendo esta atividade. Caso os estudantes já estejam trabalhando com frações, com números decimais ou com porcentagens, podemos aproveitar para mostrar essas diversas representações. Neste caso estamos realizando tratamentos, pois estamos dentro do mesmo registro numérico.

Em termos de medidas de tendência central, temos a moda, que é a cor que foi mais escolhida pelas crianças - neste caso, a cor vermelha, com $34,8 \%$ da preferência. Para 
comunicar os resultados, podemos escolher a TDF, o gráfico de barras ou, ainda, o gráfico circular como objetos não ostensivos.

Agora nos resta concluir e comunicar: qual é a cor favorita da turma? Vermelha, com $34,8 \%$, seguida da cor verde, com $26,1 \%$; as duas cores têm a preferência de quase dois terços da turma. Já a cor branca não foi escolhida por ninguém.

Arruda (2017) realizou uma intervenção com estudantes do $3^{\circ}$ ano e trabalhou a variável "Fruta preferida da turma", entregando uma ficha para marcar (Figura 9a). Em seguida solicitou aos estudantes que, em um pedaço padronizado de papel, desenhassem a fruta escolhida, construindo o pictograma no chão (Figura 9b); depois construíram o gráfico de barras no papel branco (sem marcações), desenhando a barra com as marcas de cada quadradinho (Figura 9c); em seguida, desenharam no papel quadriculado, que tem marcações para cada quadradinho (Figura 9d); e, finalmente, construíram o gráfico de barras na cartolina, utilizando faixas contínuas, como ilustrado na Figura 9e.

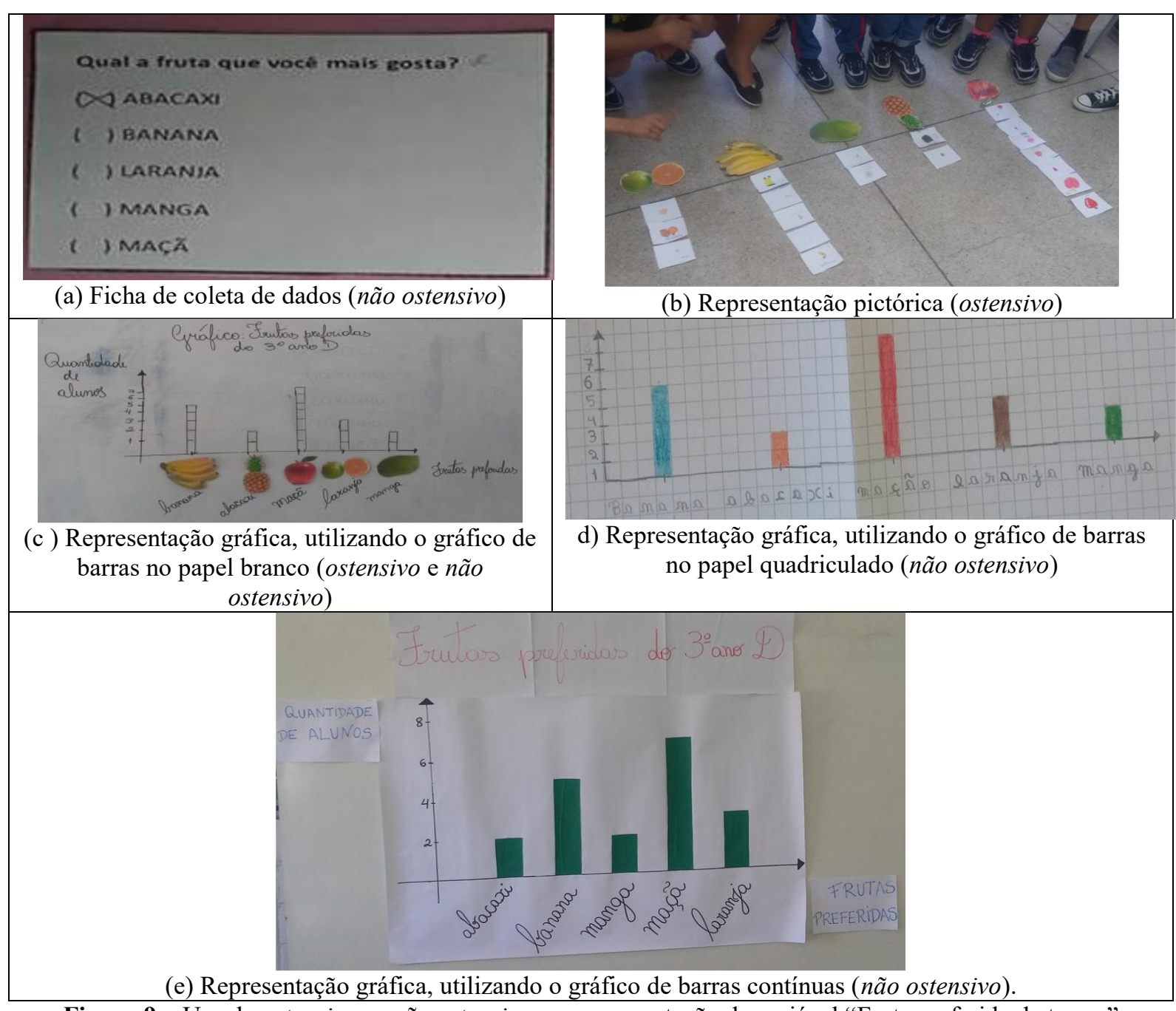

Figura 9 - Uso de ostensivos e não ostensivos na representação da variável "Fruta preferida da turma" Fonte: Arruda (2017, p. 51). 
Podemos observar que esta autora percorreu todas as fases da transformação dos dados em registro gráfico. Vemos também que os estudantes mobilizaram as regras de conformidade deste registro, organizando adequadamente os dados em gráfico de barras.

Um outro ponto para discussão é que, em tese, a variável qualitativa deveria ser representada por uma única cor, como o fez Arruda na Figura 9e. Esta convenção faz sentido, pois, se estivéssemos trabalhando com duas variáveis - por exemplo, a cor favorita por gênero -, utilizaríamos um gráfico de barras lado a lado, aplicando duas cores para diferenciar os gêneros. Seria inviável distinguir dois gêneros a partir do Gráfico da Figura 6d.

Neste ponto, observamos que diversos autores utilizam diferentes cores para cada categoria, o que está em consonância com o gráfico de setores, em que utilizamos cores diferentes para representar cada categoria, mas que não é desejável, pois estamos representando uma única variável. Esses pequenos deslizes conceituais vão se avolumando ao longo dos anos escolares, deixando confuso o estudante, que terá de usar as cores quando chegar na análise bivariada, para diferenciar as categorias da segunda variável.

As variáveis até aqui apresentadas são denominadas de empíricas, isto é, aquelas que têm referência no mundo real (CAZORLA; SILVA JUNIOR; SANTANA, 2018) com propriedades ostensivas, como, por exemplo, a cor favorita, a idade, o número de irmãos etc.

Nos levantamentos em situação escolar também podemos trabalhar com variáveis conceituais ou teóricas, que não têm, necessariamente, as propriedades ostensivas no mundo real, em primeira instância, mas precisam de instrumentos ostensivos para as suas apreensões perceptíveis e tangíveis à mão livre.

Estas variáveis em geral estão ligadas aos sentimentos, à percepção, a atitudes, dentre outros aspectos, e são denominadas também de "constructos", pois estão ligadas ao comportamento humano e, consequentemente, aos objetos não ostensivos.

Nesse sentido, Buehring (2006) trabalhou com crianças do $1^{\circ}$ ano do Ensino Fundamental, que ainda não estavam totalmente alfabetizadas, com o tema "Do que você tem mais medo". A autora solicitou que as crianças desenhassem os seus medos em um pedaço de papel padronizado. Ancorada na TRRS, a autora trabalhou com as crianças a conversão de dados do registro da língua materna para o registro gráfico e o numérico - esse último, mediante a mobilização de tabelas. A autora também utilizou caixas de fósforos, em que cada criança escrevia o seu nome e depois ela as empilhava segundo o gênero.

Souza (2007) desenvolveu, com crianças da Educação Infantil em processo de alfabetização, "O projeto das crianças" em que os alunos realizaram uma pesquisa na escola para saber o quanto as crianças gostavam da merenda da escola. Levantaram seis variáveis: 
quatro empíricas (idade, gênero, como você vem para escola e a que horas você vai dormir) e duas conceituais (gosta da escola e o que acha da merenda) e utilizaram três carinhas, representando: não gosto, indiferente e gosto.

Quando trabalhamos com variáveis conceituais, precisamos construir instrumentos que sejam capazes de traduzir esses sentimentos em categorias ou escalas que nos permitam a sua "mensuração" ou apreensão. Por exemplo, podemos trabalhar com os estudantes a variável: "Gosto pela Matemática", utilizando carinhas que representam as categorias, conforme mostrado na Figura 10.

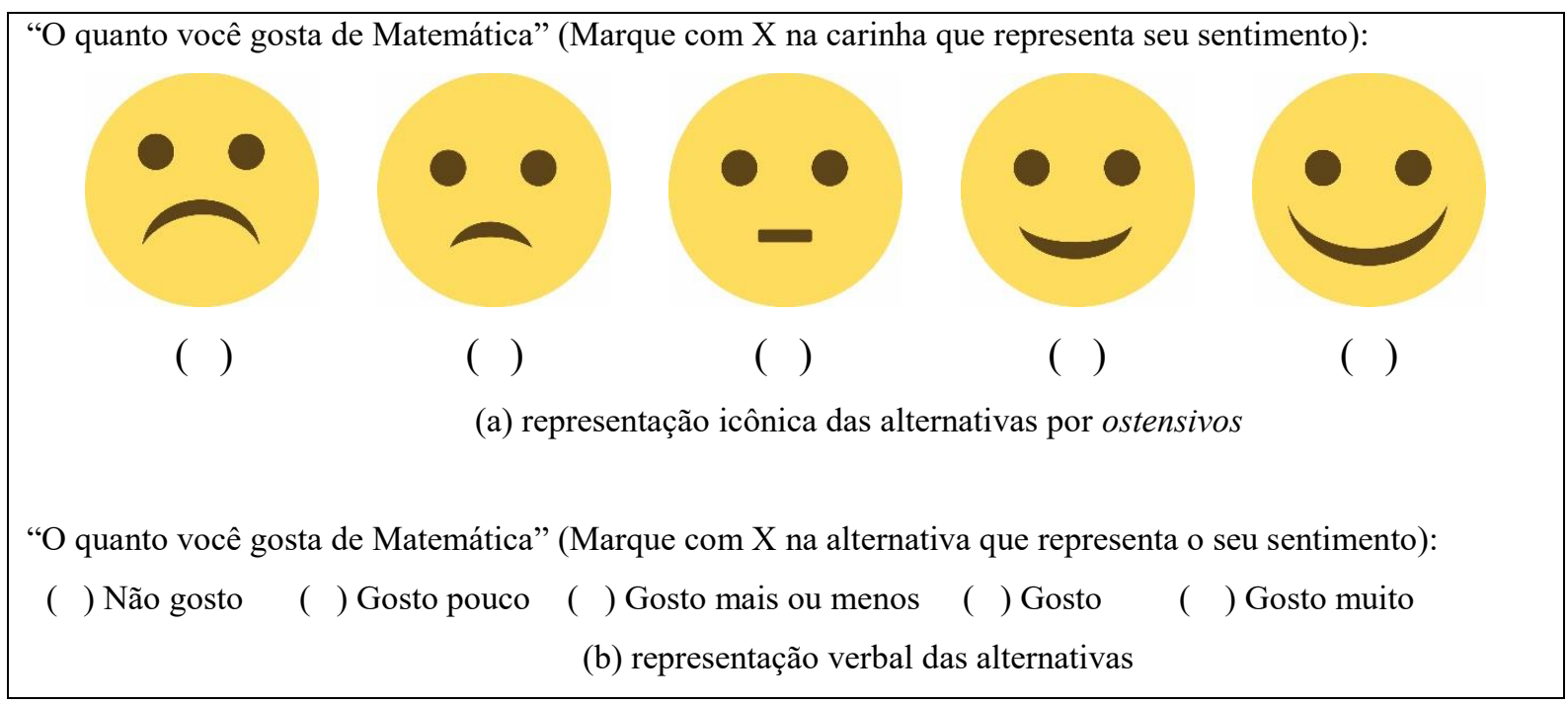

Figura 10 - Representação das alternativas das variáveis conceituais ordinais Fonte: Construção dos autores (2020).

Na literatura sobre a Educação Estatística na Educação Infantil ou nos Anos Iniciais do Ensino Fundamental encontramos trabalhos nos quais os pesquisadores têm utilizado diversos ostensivos, bastante interessantes, sendo que as atividades desenvolvidas trabalham a seriação, a ordenação, o campo aditivo, o sistema de numeração decimal, as operações fundamentais, dentre outros, utilizando o material dourado, as barras de Cusinaire, o ábaco, o soroban, o quadro valor e lugar, a utilização dos dedos pelas crianças, dentre outros ostensivos, como pontuado por Kaspary e Bittar (2014).

\section{Considerações finais}

Trabalhar sequências de ensino envolvendo os estudantes desde a coleta de dados até a comunicação dos resultados, acompanhando os diversos tratamentos e conversões, permite-lhes acompanhar as transformações dos dados em gráficos, tabelas e medidas resumo, possibilitando-lhes maior compreensão do sentido e do significado dos conceitos estatísticos. 
Neste trabalho defendemos a importância dos objetos ostensivos, em especial, nos Anos Iniciais do Ensino Fundamental, quando a criança ainda opera no concreto, isto é, na manipulação direta dos objetos ostensivos à mão livre e, consequentemente, com o contato direto dos objetos não ostensivos correspondentes. O trabalho envolvendo a criança no processo de coleta, organização e análise dos dados tem proporcionado resultados positivos, como mostram as pesquisas citadas neste artigo.

Nesse sentido advogamos que os professores utilizem os objetos ostensivos, que facilitam o acesso aos conhecimentos visados, propiciando, assim, que o estudante compreenda os conceitos estatísticos. Em especial, na sua primeira relação com o tratamento dos dados em qualquer instituição, pois, à medida que essa relação evolui, é possível que a manipulação direta dos objetos ostensivos seja dispensada, concentrando-se, essencialmente, nos objetos não ostensivos.

Neste trabalho limitamo-nos à análise univariada de variáveis qualitativas. É preciso avançar na análise bivariada e de variáveis quantitativas, a fim de fornecer um quadro teórico capaz de auxiliar os professores, quando precisam lidar com as diversas variáveis estatísticas.

\section{Referências}

ARRUDA, T. C. A Educação Estatística no ciclo da alfabetização: problematizando os gráficos. 2017. Monografia (Graduação em Pedagogia) - Universidade Federal da Paraíba, João Pessoa, 2017.

BATANERO, C. Didactica de la Estadística. Universidad de Granada. Departamento de Didáctica de la Matemática. 2001. Disponível em: http://www.ugr.es/ batanero. Acesso em: 20 dez. 2019.

BEZERRA, L.; GUIMARÃES, G. Objetos matemáticos em livros didáticos do Ensino Fundamental: conceitos de Estatística. In: CONTRERAS, J. et al. (ed.). Actas del Segundo Congreso International Virtual sobre el Enfoque Ontosemiótico del Conocimiento y la Instrucción Matemáticos.

Granada, 2017. p. 1-10. Disponível em: enfoqueontosemiotico.ugr.es/civeos.html. Acesso em: 20 dez. 2019.

BRASIL. Ministério da Educação. Secretaria de Educação Fundamental. Parâmetros Curriculares Nacionais: Matemática. Brasília: MEC/SEF, 1997.

BRASIL. Ministério da Educação. Secretaria de Educação Fundamental. Parâmetros Curriculares Nacionais: Matemática. Brasília: MEC/SEF, 1998.

BRASIL. Ministério da Educação. Orientações curriculares para o ensino médio. Volume 2: Ciências da Natureza, Matemática e suas Tecnologias. Brasília: MEC/ SEB, 2006.

BRASIL. Ministério da Educação. Base Nacional Comum Curricular. Brasília: MEC, 2018. Disponível em:

http://basenacionalcomum.mec.gov.br/images/historico/BNCC_EnsinoMedio_embaixa_site_110518.p df. Acesso em: 20 out. 2019. 
BUEHRING, R. Análise de dados no início da escolaridade: uma realidade de ensino por meio dos registros de representação semiótica. 2006. Dissertação (Mestrado em Educação Científica e Tecnológica) - Programa de Pós-Graduação em Educação Científica e Tecnológica, Universidade Federal de Santa Catarina, Florianópolis. Disponível em: http://repositorio.ufsc.br/xmlui/handle/123456789/88820. Acesso em: 20 dez. 2019.

CAZORLA, I. A relação entre a habilidade viso-pictórica e o domínio de conceitos estatísticos na leitura de gráficos. 2002. 315 f. Tese (Doutorado em Educação Matemática), Programa de PósGraduação em Educação da Faculdade de Educação, UNICAMP, Campinas, Disponível em: http://repositorio.unicamp.br/jspui/bitstream/REPOSIP/250925/1/Cazorla_IreneMauricio_D.pdf. Acesso em: 18 dez. 2019.

CAZORLA I.; SANTANA, E. Tratamento da Informação para o Ensino Fundamental e Médio. Itabuna, BA: Via Litterarum, 2006.

CAZORLA, I.; SANTANA, E. (Org.). Do Tratamento da Informação ao Letramento Estatístico. Itabuna: Via Litterarum, 2010.

CAZORLA, I.; KATAOKA, V.; SILVA, C. Trajetórias e perspectivas da Educação Estatística no Brasil: um olhar a partir do GT 12. In: LOPES, C.; COUTINHO, C.; ALMOULOUD, S. (org.). Estudos e reflexões em Educação Estatística. Campinas: Mercado de Letras, 2010. p. 19-44.

CAZORLA, I. et al. (Org.). Estatística para os Anos Iniciais do Ensino Fundamental. 2017. Sociedade Brasileira de Educação Matemática, Biblioteca do Educador - Coleção SBEM; 9. Disponível em: http://www.sbem.com.br/files/ebook_sbem.pdf. Acesso em: 10 dez. 2019.

CAZORLA, I.; SILVA JUNIOR, A; SANTANA, E. Reflexões sobre o ensino de variáveis conceituais na educação básica. REnCiMa, v. 9, n. 2, p. 354-373, 2018.

CAZORLA, I., SANTANA, E.; UTSUMI, M. O campo conceitual da média aritmética: uma primeira aproximação conceitual. Revemat, v. 14, Edição Especial Educação Estatística, p. 1-21, 2019.

CAZORLA, I., SANTANA, C. V. O cubo estatístico: material para trabalhar variáveis estatísticas. 2020. In. X Congreso Internacional sobre enseñanza de las Matemáticas. Disponível em:

http://congreso.pucp.edu.pe/xciem/wp-

content/uploads/sites/59/2019/02/XCIEM_programa_resumenes_14_02_2020.pdf. Acesso em: 27 mai. 2020.

CHEVALLARD, Y. Concepts fondamentaux de la didactique: perspectives apportées par une approche anthropologique. Recherches en Didactique des Mathématiques, Grenoble, v. 12, n. 1, p. 73-112, 1992.

COBB, G.; MOORE, D. Mathematics, statistics, and teaching. The American Mathematical Monthly, London, v. 104, n. 9, p. 801-823, 1997.

DÍAZ-LEVICOY, D. et al. Gráficos estadísticos en libros de texto de Educación Primaria: un estudio comparativo entre España y Chile. Bolema, Rio Claro, v. 30, n. 55, p. 713-737, 2016.

DUVAL, R. Registres de représentation sémiotique et fonctionnement cognitif de la pensée. In Annales de didactique et de sciences cognitives. Strasbourg: IREM, v. 5, p. 35-65, 1993.

DUVAL, R. Sémiosis et pensée humaine. Bern: Peter Lang, 1995.

DUVAL, R. Semiósis e pensamento humano: registro semiótico e aprendizagens intelectuais. São 
Paulo: Editora Livraria da Física, 2009.

ESTEVAM, E.; KALINKE, M. Recursos tecnológicos e ensino de estatística na Educação Básica: um cenário de pesquisas brasileiras. Revista Brasileira de Informática na Educação, Porto Alegre, v. 21, n. 2, p. 104-117, 2013.

GAL, I. Adults' statistical literacy: Meanings, components, responsibilities. International Statistical Review, Voorburg, v. 70, n. 1, p. 1-25, 2002.

GARFIELD, J.; BEN-ZVI, D. Developing students' statistical reasoning: Connecting research and teaching practice. New York: Springer, 2008.

GUIMARÃES, G. et al. A Educação estatística na educação infantil e nos anos iniciais. Zetetiké, Campinas, v. 17, n. 32, p. 11-28, 2009.

HENRIQUES, A. Saberes Universitários e as suas relações na Educação Básica - Uma análise institucional em torno do Cálculo Diferencial e Integral e das Geometrias. Itabuna, BA: Via Litterarum, 2019.

KASPARY, D.; BITTAR, M. A redução ostensiva no estudo das operações de adição e de subtração em uma coleção de livros didáticos dos anos iniciais. Caminhos da Educação Matemática em Revista, Aracaju, v. 2, n. 1, p. 1-14, 2014. Disponível em:

https://aplicacoes.ifs.edu.br/periodicos/index.php/caminhos_da_educacao_matematica/article/view/18. Acesso em: 18 dez. 2019.

SILVA, E. Como são propostas pesquisas em livros didáticos de Ciências e Matemática dos anos iniciais do Ensino Fundamental. 2013. Dissertação (Mestrado em Educação Matemática e Tecnológica) - Programa Edumatec, Universidade Federal de Pernambuco, Recife, 2013.

SILVA JUNIOR, A. Efeitos do ciclo investigativo PPDAC e das transformações de representações semióticas no desenvolvimento de conceitos estatísticos no ensino fundamental. 2018. Dissertação (Mestrado em Educação Matemática) - Programa de Pós-graduação em Educação Matemática, Universidade Estatual de Santa Cruz, Ilhéus, 2018.

SOUZA, A. C. A Educação Estatística na infância. 2007. Dissertação (Mestrado em Educação em Ciências e Matemática) - Programa de Pós-graduação em Educação em Ciências e Matemática, Universidade Cruzeiro do Sul, São Paulo, 2007.

SOUZA, M.; TINTI, D. O laboratório de ensino de Matemática e o ensino de Estatística: socializando reflexões e possibilidades a partir de uma vivência no curso Licenciatura em Matemática. In:

ENCONTRO NACIONAL DE EDUCAÇÃO MATEMÁTICA, 11., 2013, Curitiba. Anais... Curitiba: SBEM, 2013. p. 1-9. Disponível em: http://sbem.iuri0094.hospedagemdesites.ws/anais/XIENEM/pdf/3094_1728_ID.pdf. Acesso em: 20 dez. 2019.

STRAUSS, S.; BICHLER, E. The development of children's concepts of the arithmetic average. Journal for Research in Mathematics Education, Nova Iorque, v. 19, n. 1, p. 64-80, 1988.

WALICHINSKI, D.; SANTOS JUNIOR, G.; ISHIKAWA, E. C. M. Educação estatística e parâmetros curriculares nacionais: algumas considerações. R.B.E.C.T., Curitiba, v. 7, n. 3, p. 44-62, 2014.

WILD, C.; PFANNKUCH, M. Statistical thinking in empirical enquiry. International Statistical Review, Voorburg, v. 67, p. 223-65, 1999.

WILD, C.; UTTS, J.; HORTON, N. What is Statistics. In: BEN-ZVI, D.; MAKAR, K.; GARFIELD, J. 
(ed.). International Handbook of Research in Statistics Education. Gewerbestrasse: Springer International Handbooks of Education, 2018. Chapter 1. p. 5-36.

ZIEFFLER, A.; GARFIELD, J.; FRY, E. What is statistics education? In: BEN-ZVI, D.; MAKAR, K.; GARFIELD, J. (ed.). International Handbook of Research in Statistics Education.

Gewerbestrasse: Springer International Handbooks of Education, 2018. Chapter 2. p. 37-70.

Submetido em 20 de Dezembro de 2019. Aprovado em 04 de Junho de 2020. 